\title{
Biocontrol Activity and Plant Growth Promotion Exerted by Aureobasidium pullulans Strains
}

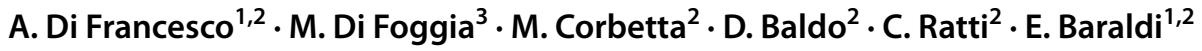

Received: 14 February 2020 / Accepted: 27 June 2020 / Published online: 8 July 2020

(c) The Author(s) 2020

\begin{abstract}
The most common leguminous plants' diseases are caused by soil-borne pathogens leading to important economic losses worldwide. Strains L1 and L8, belonging to Aureobasidium pullulans species, were tested in vitro and in vivo as biocontrol agents (BCAs) against Rhizoctonia solani (Rs1) (AG-4) and as plant growth promoters (PGPs). The non-volatile metabolites produced by L1 and L8 strains inhibited the pathogen mycelial growth by $87.9 \%$ on average, with no significant differences between the two strains. The lower pathogen diametric growth inhibition was displayed by both yeasts' volatile metabolites (VOCs) that significantly reduced the colony growth of $R$. solani, and similarly to the control, with an average of $10.5 \%$. By in vivo assay, L1 and L8 strains showed the ability to control the pathogen virulence probably through the biofilm formation around the bean and soybean plant roots, as confirmed by scanning electron microscope (SEM) analysis. The spectroscopic analysis highlighted the composition of non-volatile compounds: complex carbohydrates (pullulan), degrading enzymes, siderophores and antifungals (aureobasidins). Moreover, the ability of L1 and L8 strains to stimulate the bean and soybean plant roots, stems, and leaves growth was investigated, showing that these yeasts could have an application not only as BCAs but also as plant growth biostimulator.
\end{abstract}

Keywords Yeasts $\cdot$ Roots $\cdot$ Biofilm $\cdot$ Growth promoter $\cdot$ Metabolites

\section{Introduction}

Rhizoctonia solani represents one of the principal soil-borne pathogens that can attack a wide range of plant species, mainly leguminous plants, causing seed decay, dampingoff, hypocotyl rot, and web blight (Thiessen and Woodward 2012; Müller Schmidh et al. 2018). In particular, $R$. solani belonging to anastomosis group AG-4 represents the causal

Electronic supplementary material The online version of this article (https://doi.org/10.1007/s00344-020-10184-3) contains supplementary material, which is available to authorized users.

E. Baraldi

elena.baraldi@unibo.it

1 CRIOF, Department of Agricultural Sciences, University of Bologna, Via Gandolfi, 19, 40057 Cadriano, Bologna, Italy

2 Department of Agricultural and Food Science, University of Bologna, Viale Fanin, 42, 40127 Bologna, Italy

3 Department of Biomedical and Neuromotor Sciences, University of Bologna, Via Belmeloro, 8/2, 40126 Bologna, Italy agent of root rot of plants under greenhouse and field conditions causing great qualitative and economical damages (Ahed and Kamil 2013). Synthetic fungicides are the main systems for controlling plant diseases; however, there is a great concern for the wide use of chemical substances, due to the harmful effects on the environment and human health, and to the risk of pathogen resistance emergence. For these reasons, there is an increasing necessity to find alternative control strategies to overcome these disadvantages (Akladious et al. 2019). Alternative strategies, such as the use of antagonistic microorganisms, offer the potential to provide sustainable and long-term protection of crops (Kotze et al. 2011). The application of biological control agents (BCAs) is considered a safe and environmentally friendly alternative (Zhang et al. 2010) to synthetic fungicides. Among recent studies, the yeast Aureobasidium pullulans strains L1 and L8 (Di Francesco et al. 2018a) showed high efficacy against fruit postharvest pathogens (Di Francesco et al. 2017, 2018b, 2020a) such as Monilinia spp. and Botrytis cinerea, and also against endophytic pathogen such as Neofusicoccum parvum (Rusin et al. 2019). 
Among soil microorganisms, yeasts have received little attention as biocontrol agents of soil-borne fungal plant pathogens in comparison to bacterial, actinomycetes, and filamentous fungal antagonists (El-Tarabily and Sivasithamparam 2006). Yeasts show similar mechanisms of action against soil-borne fungal plant pathogens and plant's aerial parts pathogens (El-Tarabily and Sivasithamparam 2006). Their ability to multiply rapidly, to produce antifungal diffusible metabolites, and cell wall-degrading enzymes (CWDEs) (Kohl et al. 2019), is a hallmark for potential application as soil BCAs and plant growth promoters (PGPs).

In the present study, the efficacy of volatile and nonvolatile metabolites, produced by A. pullulans strains L1 and L8 in inhibiting growth and enzymatic activity of the soil-borne pathogen $R$. solani of bean and soybean plants, was assayed in vitro. Moreover, the composition of the nonvolatile compounds was analyzed for the first time through Fourier transform infrared spectroscopy (FT-IR) and Raman spectroscopies. In particular, the biofilm formation (polysaccharide matrices) of both strains was confirmed by scanning electronic microscopy (SEM). Subsequently, the antagonistic activity of both strains was evaluated by in vivo assays against the pathogen in bean and soybean plants. This paper describes the first application of both strains as BCAs of a soil-borne fungal plant pathogen and as PGPs.

\section{Materials and Methods}

\section{Antagonists}

Aureobasidium pullulans strains L1 and L8, molecularly characterized by Di Francesco et al. (2018a), were grown on nutrient yeast dextrose agar (NYDA: $8 \mathrm{~g}$ of nutrient broth, $5 \mathrm{~g}$ of yeast extract, $10 \mathrm{~g}$ of dextrose, and $25 \mathrm{~g}$ of technical agar, Oxoid Basingstoke-UK) in $1 \mathrm{~L}$ of distilled water. Each antagonist was grown on NYDA at $25^{\circ} \mathrm{C}$ for $48 \mathrm{~h}$ before the beginning of the experiments, and yeast cells were collected in sterile distilled water containing $0.05 \%$ (v/v) Tween 80 (Sigma-Aldrich, St. Louis, MO, USA) then adjusted with a hemocytometer to a final concentration of $10^{8}$ cells $/ \mathrm{mL}$.

\section{Pathogen}

Rhizoctonia solani isolate $(R s 1)$ used in the present experiments was obtained from symptomatic bean plants (Phaseolus vulgaris L.) grown in an experimental field located in Cadriano (Bologna, Italy), molecularly identified, and deposited to Criof mycological collection. The isolate was chosen for its highly virulent behavior. For in vitro experiments, the isolate was maintained on potato dextrose agar
(PDA, $39 \mathrm{~g}$ in $1 \mathrm{~L}$ of distilled water) (Oxoid, Basingstoke, UK) at $25^{\circ} \mathrm{C}$ for 5 days until use.

For in vivo experiments, the inoculum for infecting plants was prepared by cutting $6 \mathrm{~mm}$ diameter plugs taken from the margin of 5 days-old fungal colony and was transferred to flasks with $50 \mathrm{~mL}$ of potato dextrose broth (PDB, $39 \mathrm{~g}$ in $1 \mathrm{~L}$ of distilled water) (Oxoid, Basingstoke, UK) and incubated at $25^{\circ} \mathrm{C}$ in a rotary shaker $(250 \mathrm{rpm})$ for 5 days. The culture was then centrifuged at $5000 \times g$ for $20 \mathrm{~min}$ at $4{ }^{\circ} \mathrm{C}$, and the mycelium was washed with distilled water, filtered through two layers of miracloth, finally homogenized by using a mixer (Imetec Ch4, Italy) and immediately used for the inoculation of plant pots.

\section{Plants}

Bean (Phaseolus vulgaris L.) and soybean (Glycine max L.) plants were obtained from seeds cv 'Borlotto' and cv 'Demetra' respectively (Syngenta, Switzerland) seeded in $50 \mathrm{~mL}$ pots filled with moss, until the 2 expanded leaves stage (15 days), under daylight conditions at $25 \pm 2{ }^{\circ} \mathrm{C}$ and $60 \%$ of relative humidity $(\mathrm{RH})$.

\section{In Vitro Assays: Yeasts Metabolites Effect on Rhizoctonia solani Mycelial Growth}

Metabolites produced by both strains L1 and L8 were assayed on $R$. solani mycelial growth by three in vitro experiments. The yeast-pathogen direct interaction was firstly determined in co-culturing conditions, and then the effect of volatile and non-volatile compounds produced by both strains on pathogen growth was verified. The direct interaction assay between yeasts and the pathogen was assayed on PDA medium in $90 \mathrm{~mm}$ diameter Petri plates. Pathogen mycelial plug (6 $\mathrm{mm}$ diameter) cut from the margin of a 5 days-old colony was inoculated in the center of the plate and L1 and L8 cells, taken from $48 \mathrm{~h}$ cultures grown on NYDA, were streaked on the plate $22.5 \mathrm{~mm}$ from both sides of the pathogen plug through a sterile loop. In control plates, yeasts cells were not inoculated.

Plates were incubated at $25^{\circ} \mathrm{C}$ for 5 days and the diameter of the pathogen colony was measured on a line passing along the center of the plug and perpendicular to yeast streaks, after 3,4 , and 5 days of incubation. For each strain and the control, 10 agar plates were used, and the assay was repeated twice. To verify the effect of volatile compounds produced by L1 and L8 strains on $R$. solani mycelium growth the double Petri dishes assay was used as previously described by Di Francesco et al. (2015). For this purpose, NYDA plates were inoculated by spreading $100 \mu \mathrm{L}$ of antagonist cells suspension $\left(10^{8}\right.$ cells $\left./ \mathrm{mL}\right)$. The lid of the plate was replaced, after $48 \mathrm{~h}$ of incubation at $25^{\circ} \mathrm{C}$, by a base plate of PDA inoculated with a $6 \mathrm{~mm}$ diameter pathogen plug cut 
from the margin of a 5 days-old colony. The two base plates were sealed immediately with a double layer of Parafilm and incubated at $25^{\circ} \mathrm{C}$ for 5 days. Control was represented by plates inoculated only with the pathogen. To verify the further effect of yeasts metabolites on pathogen mycelium growth, at the end of the incubation time, the weight of each dish was measured. The sample unit was represented by ten plates (replicates) for the control and each antagonist. The assay was repeated twice. To verify the effect of L1 and L8 non-volatile metabolites, $100 \mu \mathrm{L}$ of antagonist cells suspension $\left(10^{8}\right.$ cells $\left./ \mathrm{mL}\right)$ were spread on a sterile cellophane disc (Courtauld Films: $90 \mathrm{~mm}$ diameter) laying down on PDA medium plate and incubated at $25{ }^{\circ} \mathrm{C}$ for $48 \mathrm{~h}$. The cellophane with the yeast was then removed and, a $6 \mathrm{~mm}$ diameter pathogen plug, cut from the margin of a 5 days-old colony and incubated at $25^{\circ} \mathrm{C}$ for 5 days, was positioned at the center of the plate. One hundred microliters of sterile water were streaked on cellophane representing the control. The sample unit was represented by ten plates (replicates) for the control and each antagonist. The assay was repeated twice.

\section{Synthetic Volatile Compounds Effect on Rhizoctonia solani Mycelial Growth}

Di Francesco et al. (2015) identified through headspace solid-phase microextraction (HS-SPME-GCMS) the volatile compounds produced by L1 and L8. For this purpose, pure standards of 3-methyl-1-butanol, 2-methyl-1-butanol, 2-methyl-1-propanol and 2-phenylethanol (Sigma-Aldrich, St. Louis, MO) were tested on $R$. solani colony growth. Different aliquots of pure compounds 25,50 and $100 \mu \mathrm{L}$, were placed with a microsyringe on a filter paper (Whatman No. 1, $90 \mathrm{~mm}$ diameter) positioned inside the cover of a PDA dish previously inoculated with a $6 \mathrm{~mm}$ diameter pathogen plug cut from the margin of a 5 days-old colony. The aliquots of pure compounds introduced in the Petri dishes corresponded to $2.25,1.12$ and $0.56 \mu \mathrm{L} / \mathrm{mL}$ headspace. The dishes were quickly closed, sealed with Parafilm and incubated at $20{ }^{\circ} \mathrm{C}$. The activity of each pure compound against mycelial growth was evaluated after 5 days of incubation. In the controls, pure compounds were substituted by equivalent amounts of distilled water. The sample unit was represented by 5 plates for each volatile compound concentration. $\mathrm{EC}_{50}$ values were calculated as the headspace concentrations $(\mu \mathrm{L} /$ $\mathrm{mL}$ ) that inhibited mycelial growth by $50 \%$ compared to the control. The experiment was performed twice.

\section{Volatile Compounds Effect on Rhizoctonia solani Pathogenesis Enzymes Activity}

To verify the effect of volatile compounds produced by L1 and L8 strains on $R$. solani pathogenesis enzymes, the fungal mycelium derived from the double Petri dishes assay exposed or not to yeasts VOCs, was used to perform cellulase, xylanase, polygalacturonase, and pectinase assays. The enzymes agar composition was previously reported in Di Francesco et al. (2018c, 2020b). Assays were performed in Petri dishes containing specific agar medium. Twenty mycelial agar plugs $(6 \mathrm{~mm}$ diameter) derived from each yeast VOCs treatment and the control were placed equidistant $(3 \mathrm{~cm})$ on each enzyme agar plate $(30 \times 30 \times 2 \mathrm{~cm}$. $L \times W \times H)$ and incubated at $25^{\circ} \mathrm{C}$ for $24 \mathrm{~h}$. Enzymes activities were determined with specific colorimetric methods, described by Di Francesco et al. (2018c, 2020b), which have allowed visualizing a clear zone of substrate degradation around each plug.

The diameter of degradation halos $(\mathrm{mm})$ was measured with a ruler. Each enzyme assay was repeated twice.

\section{Non-volatile Metabolites Analysis}

Flasks containing $100 \mathrm{~mL}$ of nutrient yeast dextrose broth (NYDB) medium were inoculated with $100 \mu \mathrm{L}$ of antagonists cells suspensions $\left(10^{8}\right.$ cells $\left./ \mathrm{mL}\right)$ and then incubated at $25{ }^{\circ} \mathrm{C}$ in a rotary shaker $(250 \mathrm{rpm})$ for 1,24 and $48 \mathrm{~h}$. After each incubation time, the liquid cultures were centrifuged at $5000 \times g$ for $20 \mathrm{~min}$ at $15^{\circ} \mathrm{C}$ and the supernatant was collected in sterile tubes $(2 \mathrm{~mL})$ and stored at $-20^{\circ} \mathrm{C}$. The control consisted of growth medium without yeast cells inoculation. The supernatant was analyzed by two different spectroscopic techniques (FT-IR and Raman) to obtain a rapid and non-destructive characterization of their main molecular components. Infrared spectra were recorded with a Bruker ALPHA series FT-IR spectrophotometer (Bruker, Ettlingen, Germany) equipped with an apparatus for attenuated total reflectance (Diamond crystal). The spectra were collected from 4000 to $400 \mathrm{~cm}^{-1}$ and averaged over 100 scans (resolution $=4 \mathrm{~cm}^{-1}$ ): 4 spectra were measured for each sample for each sampling time. Raman spectra were recorded on a Bruker MultiRam FT-Raman spectrometer equipped with a cooled Ge-diode detector. The excitation source was a neodymium-doped yttrium aluminum garnet $\left(\mathrm{Nd}^{3+}\right.$-YAG) laser $(1064 \mathrm{~nm})$ in the backscattering configuration. The power delivered from the focused laser to sample has been measured to be $\sim 200 \mathrm{~mW}$. The spectra were collected from 4000 to $200 \mathrm{~cm}^{-1}$ and averaged over 10,000 scans (resolution $=4 \mathrm{~cm}^{-1}$ ).

\section{Biofilm Formation}

Biofilm formation was evaluated following a procedure previously described by Parafati et al. (2015), partially modified. Yeast strains were grown overnight at $25^{\circ} \mathrm{C}$ in liquid medium (NYDB) in a rotary shaker $(250 \mathrm{rpm})$. Cells were then collected, washed twice with phosphate-buffered saline 
(PBS, pH 7.2), and re-suspended in NYDB to $10^{7}$ cells $/ \mathrm{mL}$. Aliquots of cell suspensions $(100 \mu \mathrm{L})$ were inoculated into the wells of a 96-well polystyrene plate and incubated at $25{ }^{\circ} \mathrm{C}$ for $3 \mathrm{~h}$ in a rotary shaker $(100 \mathrm{rpm})$; the medium without yeasts cells was used as control. After this period, the wells were washed once with $150 \mu \mathrm{L}$ of PBS, and $100 \mu \mathrm{L}$ of NYDB were transferred into each washed well. The plates were incubated at $25{ }^{\circ} \mathrm{C}$ in agitation $(100 \mathrm{rpm})$ for 3,24 , and $48 \mathrm{~h}$. The medium was replenished daily by aspiration of the spent medium and the addition of the fresh medium. After each incubation time, wells were washed twice with PBS and stained with $100 \mu \mathrm{L}$ of $0.4 \%$ aqueous crystal violet solution for $45 \mathrm{~min}$. The wells were washed four times with sterile distilled water (SDW) and destained with $200 \mu \mathrm{L}$ of 95\% ethanol. After $45 \mathrm{~min}, 100 \mu \mathrm{L}$ of the destaining solution was transferred to a new 96-well plate and the amount of crystal violet was measured at $590 \mathrm{~nm}$ with a spectrophotometer (Infinite ${ }^{\circledR}$ F50 Tecan, Männedorf, $\mathrm{CH}$ ). The controls' absorbance values were subtracted from the test well values to minimize background interference. The assay was repeated twice.

\section{In Vivo Assays}

Roots plants were immersed in $25 \mathrm{~mL}$ of yeasts cells suspensions $\left(10^{8}\right.$ cells $\left./ \mathrm{mL}\right)$ for $1 \mathrm{~h}$. Plants were then transplanted in a new plot where $R$. solani mycelium was inoculated $24 \mathrm{~h}$ earlier ( $1 \mathrm{~g}$ per $220 \mathrm{~g}$ of peat moss) (1 plant per pot). The control consisted of roots plants treated with water only. The sample unit was represented by ten plants (replicates) for each yeast strain and the control. After the stem-end symptom appearance ( 21 days) the disease incidence was evaluated and a Koch postulate was conducted.

Hypocotyls with severity of $R$. solani of each plant were evaluated using a $0-4$ scale developed by Cardoso and Echandi (1987) with some modifications, where $0=$ no lesions, $1=$ lesions $<2.5 \mathrm{~mm}, 2=$ lesions $2.5-5 \mathrm{~mm}$, $3=$ lesions $>5 \mathrm{~mm}, 4=$ lesions girdling plant and wilting visible on leaves. A disease severity index (DSI) was calculated for each treatment using the formula:

DSI $=\frac{\text { percentage of incidence } \times \text { mean severity }}{5}$.

To evaluate the yeast strains growth promotion effect on bean and soybean plants (10 plants for each strain and the control) without pathogen mycelium inoculation, the length of the roots $(\mathrm{mm})$, the stems diameter $(\mathrm{mm})$ and the leaves areas $\left(\mathrm{mm}^{2}\right)$ were measured after 21 days from the treatment of the roots by using a digital caliber (Dirtygal) and Tomato Analyzer Software (Brewer et al. 2006), respectively. Treatment effects were assayed in two independent experiments. The control consisted of roots plants treated with water only.

\section{Scanning Electron Microscopy Observation}

The biofilm formation on bean and soybean plants roots was investigated by SEM observations. Plant roots were treated with $25 \mathrm{~mL}$ of yeasts cells suspensions $\left(10^{7}\right.$ cells/ $\mathrm{mL}$ ) and the biofilm assessments were carried out after 3, 24 and $48 \mathrm{~h}$ from the treatment. Little portions of roots tissues $(3 \times 3 \times 3 \mathrm{~mm})$ were excised, washed three times for 7 min in $0.1 \mathrm{M}$ Phosphate buffer $\mathrm{pH}$ 7.2. Three samples from each plant were fixed with glutaraldehyde $3 \%$ in phosphate buffer solution at $\mathrm{pH}$ 7.4. Before observation, the fixed tissues were rinsed three times with phosphate buffer ( $\mathrm{pH} 7.4)$, dehydrated in increasing ethanol solutions $(20,30,50,75$, $95,100 \%$ ), and with the use of a conductive $3 \mathrm{M} 465 \mathrm{kp}$ scotch tape were set on aluminum pin stubs. Samples were then coated with gold particles using Emitech K500 sputter at $40 \mathrm{~mA}$ for $3 \mathrm{~min}$. Samples were observed under SEM (Philips SEM 515 microscope at $30 \mathrm{kV}$ ).

Fifteen samples derived from 5 plants were examined for each plant species, sampling time and treatment.

\section{Statistical Analysis}

All experiments were carried out in a completely randomized design. Obtained data were analyzed by one-way ANOVA $(P<0.05)$. Separation of means was performed using the least significant difference (LDS) test, at $P<0.05$. All analyses were performed with the software Statgraphic Plus Version 2.1 (Statistical Graphics Corp., USA 1996).

\section{Results}

\section{In Vitro Assays: Yeasts Metabolites Effect on Rhizoctonia solani Mycelial Growth}

The effects of L1 and L8 strains on $R$. solani mycelial growth through the direct interaction in the co-culturing condition and the exposure to non-volatile and volatile metabolites produced by the strains are reported in Table 1 . In the yeastpathogen co-culturing experiment, both L1 and L8 strains significantly reduced the pathogen colony growth compared to the control without a substantial difference between the two antagonists. However, the pathogen colony growth was inhibited by $57.3 \%$ by both strains. The non-volatile metabolites produced by L1 and L8 inhibited the pathogen mycelial growth of about $87.9 \%$, with no significant differences among the two strains. The lower pathogen colony growth inhibition was displayed by both yeasts volatile metabolites and non-volatile metabolites. In fact, the colony growth of $R$. solani was significantly reduced similarly by both strains of about $10.5 \%$ compared to the control. Nevertheless, the volatile compounds produced by both strains reduced by $60 \%$ the 
Table 1 Effect of L1 and L8 strains on the colony growth (mm) of Rhizoctonia solani $(R s 1)$ in co-culturing condition, and exposed to non-volatile and volatile metabolites, after 5 days of incubation on PDA medium

\begin{tabular}{lccl}
\hline & Co-culturing & $\begin{array}{l}\text { Non-volatile } \\
\text { metabolites }\end{array}$ & Volatile metabolites \\
\hline Control & $82 \pm 3.50 \mathrm{~b}$ & $83 \pm 1.35 \mathrm{~b}$ & $85 \pm 1.97 \mathrm{~b}$ \\
L1 & $35 \pm 1.70 \mathrm{a}$ & $9 \pm 0.94 \mathrm{a}$ & $76 \pm 3.58 \mathrm{a}$ \\
L8 & $35 \pm 0.92 \mathrm{a}$ & $11 \pm 4.84 \mathrm{a}$ & $76 \pm 1.68 \mathrm{a}$ \\
\hline
\end{tabular}

The data are the means of two independent experiments \pm standard deviation

Different letters within the same column indicate significant differences, LSD test $(P<0.05)$

Table 2 Effect of four synthetic volatile organic compounds (VOCs) emitted by the two strains of Aureobasidium pullulans (L1 and L8) on mycelial growth of Rhizoctonia solani (Rs1)

\begin{tabular}{ll}
\hline VOCs & $\mu \mathrm{L} \mathrm{mL}^{-1}$ \\
\hline 1-butanol, 2-methyl & 0.18 \\
1-butanol, 3-methyl & 0.13 \\
1-propanol, 2-methyl & 1.50 \\
Phenethyl alcohol & 0.26 \\
\hline
\end{tabular}

$\mathrm{EC}_{50}$ values $\left(\mu \mathrm{L} \mathrm{mL}^{-1}\right.$ headspace $)$ pathogen mycelial weight (data not shown). Non-volatile metabolites from both strains were significantly more effective than volatiles.

\section{Synthetic Volatile Compounds Effect on Rhizoctonia solani Mycelial Growth}

The effect of pure volatile compounds on $R$. solani colony growth is reported in Table 2. Among the four tested compounds, 2-methyl-1-butanol, 3-methyl-1-butanol, and 2-phenylethanol showed the highest efficacy in reducing pathogen growth, with $\mathrm{EC}_{50}$ values of $0.18,0.13$, and $0.26 \mu \mathrm{L} / \mathrm{mL}$, respectively. The least effective compound was 2-methyl1-propanol with an $\mathrm{EC}_{50}$ value of $1.50 \mu \mathrm{L} / \mathrm{mL}$.

\section{Volatile Compounds Effect on Rhizoctonia solani Pathogenesis Enzymes Activity}

The effect of VOCs produced by L1 and L8 was tested on the pathogenesis enzymes activity of $R$. solani. Both VOCs strains constrained the pathogenesis activity of the fungus, showing a clear reduction of the diameter of the enzymatic halo (mm) (Fig. 1). Both strains inhibited, on average, the tested fungal pathogenesis enzymes activity by $17.9 \%, 7.3 \%$, $8.4 \%, 36.1 \%$ respectively for cellulase, xylanase, polygalacturonase, and pectinase, displaying an indirect action against $R$. solani pathogenic activity. Furthermore, the xylanase enzyme resulted in the most produced by the pathogen and polygalacturonase the least.
Fig. 1 Influence of L1 and L8 volatile metabolites on Rhizoctonia solani $(R s 1)$ pathogenesis enzymes production (cellulase, xylanase, polygalacturonase, pectinase) (halo diameter) $(\mathrm{mm})$, after 5 days of exposure or not (control). Each value is the mean of 20 replicates. Different letters within the same enzyme indicate significant differences according to LSD test $(P<0.05)$

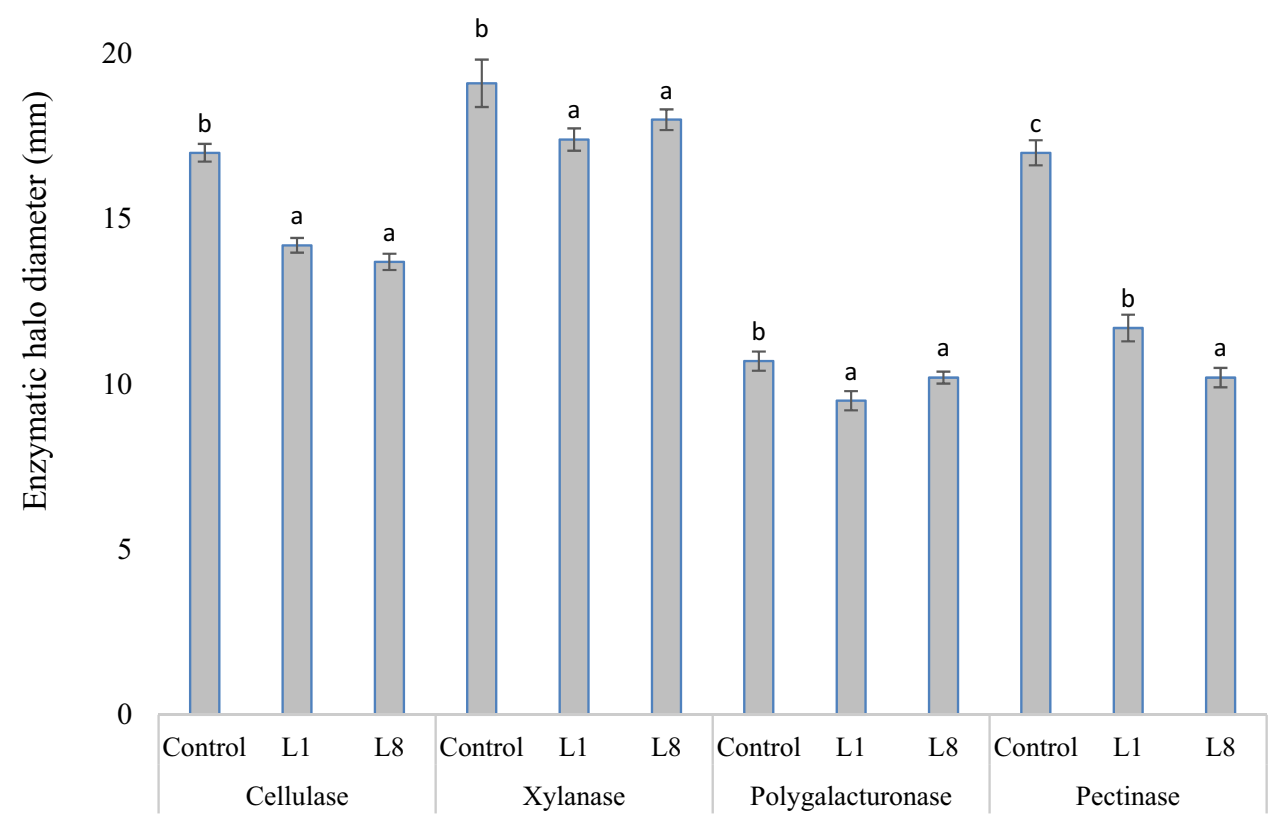




\section{Non-Volatile Compounds Analysis}

The spectroscopic measurements were carried out to determine the main non-volatile metabolites production by A. pullulans strains $\mathrm{L} 1$ and $\mathrm{L} 8$ in the liquid culture medium after 1,24 , and $48 \mathrm{~h}$ of incubation at $25^{\circ} \mathrm{C}$. Figures 2 and 3 show the main peaks related to the metabolites groups detected after 1, 24, and $48 \mathrm{~h}$ of incubation by FT-IR and Raman spectroscopies, respectively. More in detail, Figs. 2a and 3a show the FT-IR and Raman spectra of L1 metabolites, Figs. $2 b$ and $3 b$ the FT-IR and Raman difference spectra between L1 and the control medium, and Figs. $2 \mathrm{c}$ and $3 \mathrm{c}$ the FT-IR and Raman difference spectra between L1 and L8 strains after $48 \mathrm{~h}$. Spectroscopic peaks were attributed to five classes of compounds that are highlighted with different colors in the figures: nutrient medium (black peaks); complex carbohydrates (Bozoudi and Tsaltas 2018), as pullulan and other $\beta$-glucans (blue peaks); lytic enzymes (Bozoudi and Tsaltas 2018), as amylases, cellulases, lipases, xylanases, proteases, laccase and mannanases (red peaks); antifungal compounds (Bozoudi and Tsaltas 2018), as aureobasidins, derivatives of cyclic depsipeptides possessing, as typical amino acids, proline, leucine and phenylalanine (green peaks); siderophores (Bozoudi and Tsaltas 2018) (purple peaks).

The peaks attributed to the nutrient medium were derived from the FT-IR and Raman spectra of pure NYDB (data not shown), while the attribution of carbohydrates, enzymes, siderophores and aureobasidins is based on the existing literature (Aghatabay et al. 2014; Bae et al. 2015; Cozar et al. 2006; Dahiya et al. 2016; Shingel 2002; Tu 1982; Um et al. 2013; Zhbankov et al. 2000). Different spectra between L1 and the medium control (Figs. $2 b$ and $3 b$ ) were useful to discriminate the main metabolites produced by the strain (positive peaks) and the medium itself (negative peaks). In analogy, different spectra between L1 and L8 strains (Figs. 2c and 3c) allowed highlighting the production of the different metabolites by the two strains. Focusing the attention on these last two spectra (FT-IR spectrum: Fig. 2c and Raman spectrum: Fig. 3c), it is possible to state that L1 strain showed a higher production of complex carbohydrates and enzymes: the former showed negative peaks at 932 and $848 \mathrm{~cm}^{-1}$ in the IR spectrum (Fig. 2c, blue peaks)

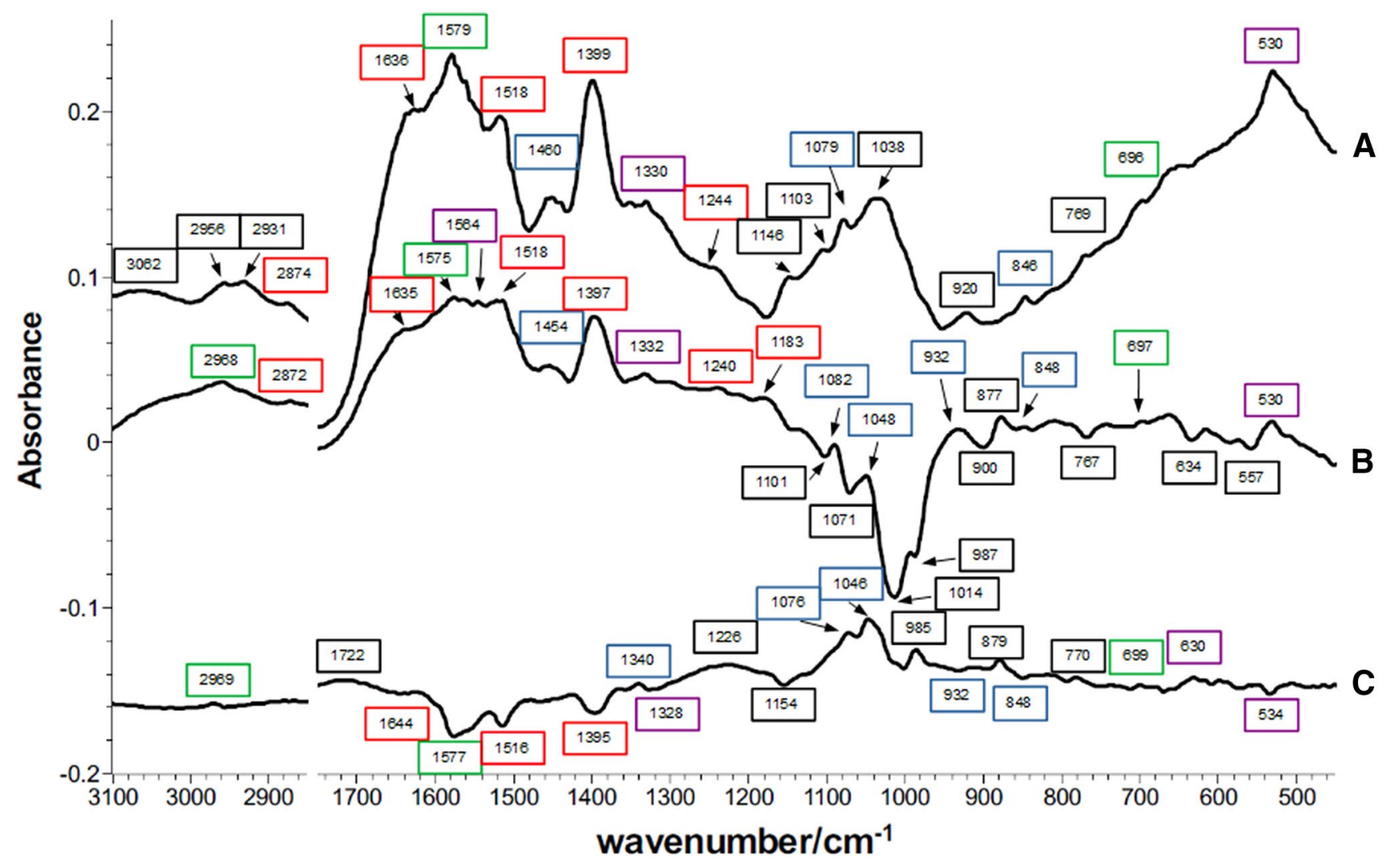

Fig. 2 FT-IR spectra of L1's metabolites (a), FT-IR difference spectra between L1 and the control medium (b), FT-IR difference spectra between L1 and L8 strains after $48 \mathrm{~h}(\mathbf{c})$. Spectroscopic peaks were attributed to: nutrient medium (black peaks); complex carbohydrates (blue peaks); lytic enzymes (red peaks); aureobasidins, (green peaks); siderophores (purple peaks). The non-volatile metabolites produced by Aureobasidium pullulans strains L1 and L8 were collected from the supernatant of the cells cultures in liquid medium (NYDB) after 1,24 , and $48 \mathrm{~h}$ of incubation at $25^{\circ} \mathrm{C}$. The spectra showed the most significant sampling time (Color figure online) 


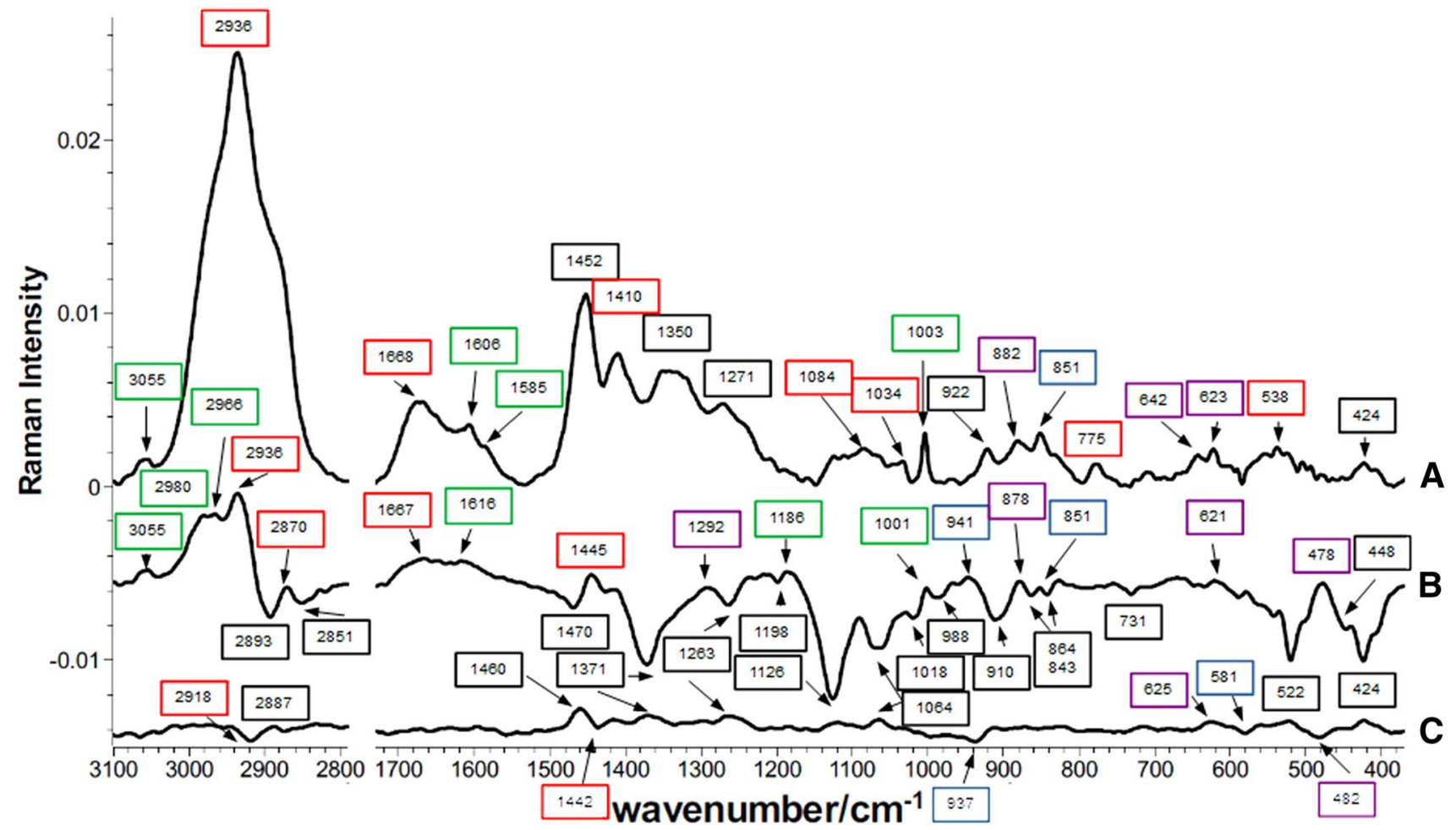

Fig. 3 Raman spectra of L1's metabolites (a), Raman difference spectra between L1 and the control medium (b), Raman difference spectra between L1 and L8 strains after $48 \mathrm{~h}$ (c). Spectroscopic peaks were attributed to: nutrient medium (black peaks); complex carbohydrates (blue peaks); lytic enzymes (red peaks); aureobasidins, (green peaks);

and 937 and $581 \mathrm{~cm}^{-1}$ in the Raman spectrum (Fig. 3c, blue peaks); the latter showed negative peaks at 1644, 1516 and $1395 \mathrm{~cm}^{-1}$ in the IR spectrum (Fig. 2c, red peaks) and 2918 and $1442 \mathrm{~cm}^{-1}$ in the Raman spectrum (Fig. 3c, red peaks). Interestingly, Fig. 2c also shows some positive peaks attributed to pullulan production at 1340,1076 and $1046 \mathrm{~cm}^{-1}$ : all these peaks are reported to be sensitive to the chain length and the molecular weight of polysaccharides (Singhel et al. 2002) and indicate a reduction of their polymeric chain. The behavior of aureobasidins and siderophores production is more complex since the difference spectra between the two strains showed both negative $\left(1577,1328\right.$ and $534 \mathrm{~cm}^{-1}$, Fig. 2c; $482 \mathrm{~cm}^{-1}$, Fig. 3c) and positive peaks (2969, 699 and $630 \mathrm{~cm}^{-1}$, Fig. $2 \mathrm{c}$ and $625 \mathrm{~cm}^{-1}$, Fig. 3c): this finding could suggest that the two strains produce different antifungal and siderophores compounds.

\section{Biofilm Formation}

Spectrophotometer assay tested the biofilm formation ability of L1 and L8 strains after 3, 24 and 48 h, as described in the previous section. Aureobasidium pullulans L1 strain after $3 \mathrm{~h}$ showed a great ability to adhere to the polystyrene siderophores (purple peaks). The non-volatile metabolites produced by Aureobasidium pullulans strains L1 and L8 were collected from the supernatant of the cells cultures in liquid medium (NYDB) after 1,24 , and $48 \mathrm{~h}$ of incubation at $25^{\circ} \mathrm{C}$. The spectra showed the most significant sampling time (Color figure online)

plates after repeated washes (OD $1.00 \pm 0.07$ ), on the contrary L8 adheres less displaying an OD value of $0.26 \pm 0.07$. Experiments also demonstrated that both strains, L1 and L8, maintained high film-forming capacity until $48 \mathrm{~h}$ (OD $1.8 \pm 0.18$ and $1.3 \pm 0.15$, respectively). Aureobasidium pullulans strain L1 exhibited a biofilm formation phase peak at 24 h of growth (Fig. 4).

\section{In Vivo Assay}

The efficacy of both L1 and L8 strains against $R$. solani in in vivo experiments was of $80 \%$ in bean plants, and $80 \%$ and $50 \%$ in soybean plant respectively, compared to the control (Table 3). Moreover, the DSI in bean was reduced by $94 \%$ by both strains and in soybean by $94 \%$ and $71 \%$ by L 1 and L8 respectively, compared to the control.

Moreover, strain L1 especially showed a stimulant effect on plant roots length, increasing by $20.4 \%$ and $24.4 \%$ bean and soybean roots length, respectively (Table 4) (Supplemental Fig. 1a). Also, the stem diameter and leaf area of both plants underwent a dimensional increase when grown with the yeasts compared to the control. For bean stem, an increase of $30 \%$ by L1 and $16.6 \%$ by L8 and for soybean 


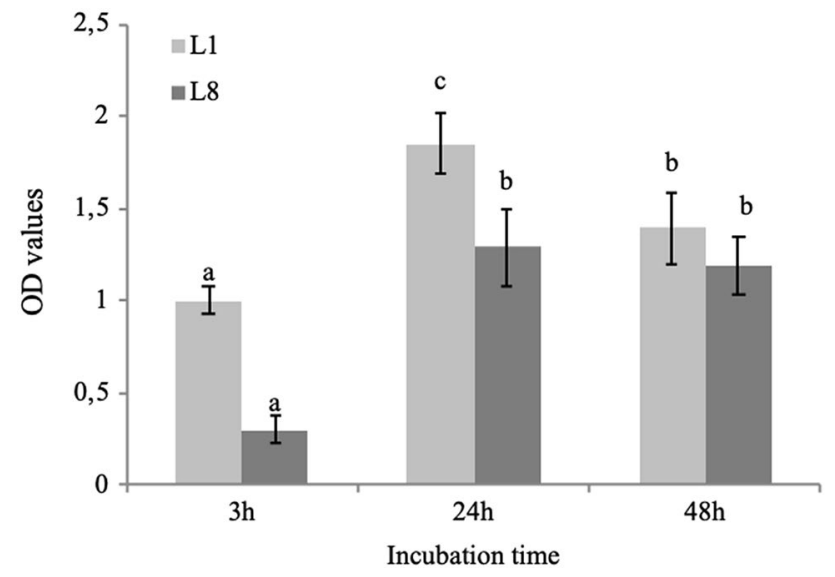

Fig. 4 Biofilm formation by Aureobasidium pullulans L1 and L8 strains on polystyrene plate measured at $590 \mathrm{~nm}$ with a spectrophotometer after 3,24 and $48 \mathrm{~h}$ of incubation at $25{ }^{\circ} \mathrm{C}$. Each value is the mean of 3 replicates \pm standard deviation. Different letters within the same strain indicate significant differences according to LSD test $(P<0.05)$

Table 3 Effect of L1 and L8 Aureobasidium pullulans strains $\left(10^{8}\right.$ cell $\mathrm{mL}^{-1}$ ) roots treatment on disease incidence (DI) and on disease severity (DSI = disease severity index) at hypocotile, caused by Rhizoctonia solani $(R s 1)$

\begin{tabular}{llc}
\hline Treatments & $\mathrm{DI}^{*}$ & $\mathrm{DSI}^{* *}$ \\
\hline Phaseolus vulgaris $\mathrm{L}$. & & \\
Control & $70 \pm 1.40 \mathrm{~b}$ & 36 \\
L1 & $20 \pm 0.44 \mathrm{a}$ & 2 \\
L8 & $22 \pm 0.34 \mathrm{a}$ & 2 \\
Glycine max L. & & \\
Control & $90 \pm 0.7 \mathrm{c}$ & 45 \\
L1 & $20 \pm 2.1 \mathrm{a}$ & 2 \\
L8 & $50 \pm 0.7 \mathrm{~b}$ & 13 \\
\hline
\end{tabular}

Treated plants (beans and soybean) were transplanted in new plots, inoculated $24 \mathrm{~h}$ before with Rhizoctonia solani $(R s 1)$ mycelium (1 g per $220 \mathrm{~g}$ of peat moss). After the stem-end symptom appearance (21 days) DI and DSI were evaluated

Means $( \pm$ SD) followed by the same letter in a column for each plant (bean and soybean) are not significantly different according to LSD test $(P<0.05)$

${ }^{*} \mathrm{DI}=$ disease incidence. Values are the mean of the two experiments \pm standard deviation

**Disease severity index (DSI) of bean and soybean was calculated by percentage of disease incidence $\times$ mean of severity $/ 5$, where severity was rated on a $0-5$ scale

stem of $53.8 \%$ only by L1 was registered. For bean leaf, L1 and L8 more than doubled the areas. An increase of $48.3 \%$ and $17.8 \%$ by $\mathrm{L} 1$ and $\mathrm{L} 8$ respectively was registered for soybean leaf areas (Supplemental Fig. 1b).
Table 4 Bean and soybean plant roots length ( $\mathrm{mm})$, stem-end diameter $(\mathrm{mm})$ and leaf area $\left(\mathrm{mm}^{2}\right)$ after 21 days from the treatment with L1 and L8 strains

\begin{tabular}{lclc}
\hline & Root length $(\mathrm{mm})$ & Stem diameter $(\mathrm{mm})$ & Leaf area $\left(\mathrm{mm}^{2}\right)$ \\
\hline Bean (Phaseulus vulgaris $\mathrm{L})$. & & \\
Control & $86.8 \pm 19.2 \mathrm{a}$ & $3.0 \pm 0.8 \mathrm{a}$ & $643.4 \pm 16.5 \mathrm{a}$ \\
L1 & $109.1 \pm 16.8 \mathrm{~b}$ & $3.9 \pm 0.7 \mathrm{c}$ & $1622.6 \pm 7.1 \mathrm{c}$ \\
L8 & $85.6 \pm 5.5 \mathrm{a}$ & $3.5 \pm 0.4 \mathrm{~b}$ & $1432.1 \pm 24.5 \mathrm{~b}$ \\
Soybean (Glycine $\max$ L.) & & \\
Control & $209 \pm 18.3 \mathrm{a}$ & $1.3 \pm 0.1 \mathrm{a}$ & $275.2 \pm 42.7 \mathrm{a}$ \\
L1 & $276.6 \pm 40.4 \mathrm{~b}$ & $2.0 \pm 0.2 \mathrm{~b}$ & $408.3 \pm 54.6 \mathrm{c}$ \\
L8 & $249.2 \pm 27.6 \mathrm{~b}$ & $1.5 \pm 0.3 \mathrm{a}$ & $324.8 \pm 19.1 \mathrm{~b}$ \\
\hline
\end{tabular}

The control consisted of roots plants treated with water only. Each value is the mean of 10 replicates \pm standard deviation

Different letters within the same measurement indicate significant differences according to LSD test $(P<0.05)$

\section{SEM Observations}

The development of biofilm structure by A. pullulans L1 and L8 strains on bean and soybean roots was assessed by observation under scanning electron microscope after 3, 24 and $48 \mathrm{~h}$ from the inoculation at room temperature, as reported in Fig. 5. Only images of L1 on bean are reported since no optical differences were founded between the two strains and the plant species. A great clustering of yeast cells formed all around the bean roots from the very first sampling time (3 h) (Fig. 5b).

Both strains colonized the surface of the roots by the biofilm formation preventing the pathogen attachment and colonization. Forty-eight hours after the inoculation, the surface of the roots was still totally covered by the yeast cells demonstrating how the biofilm structure is capable of protecting from the pathogen attack (Fig. $5 \mathrm{~d}$ ).

\section{Discussion}

In this study, A. pullulans L1 and L8 strains revealed the capability to control a soil-borne pathogen of bean and soybean plants, such as $R$. solani.

Yeasts have always received little attention as BCAs of soil pathogens compared to other microorganisms (El-Tarabily and Sivasithamparam 2006). The presence of yeasts in the soil principally depends on the amount of available nutrients and soil factors such as compaction and porosity, rainfall, cultivation, the presence of soil-inhabiting insects (Phaff et al. 1978). For these reasons, yeasts were mainly studied for the biocontrol of postharvest and foliar diseases probably because they are a major component of the leaves and other plants' aerial parts surfaces (Wilson and Wisniewski 1989; McLaughlin et al. 1990; Filonow 1998). The most frequently 

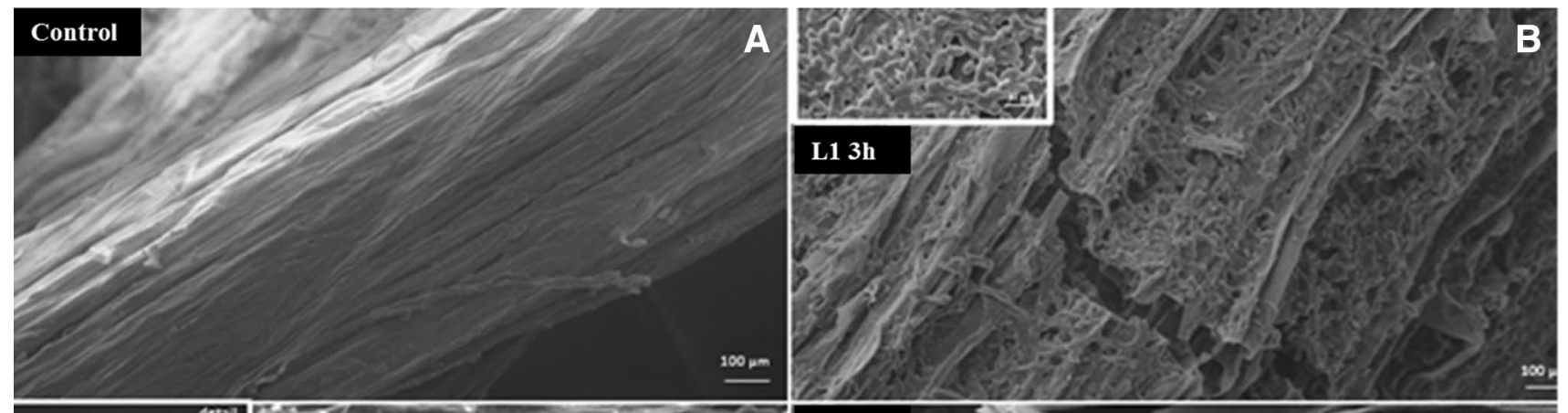
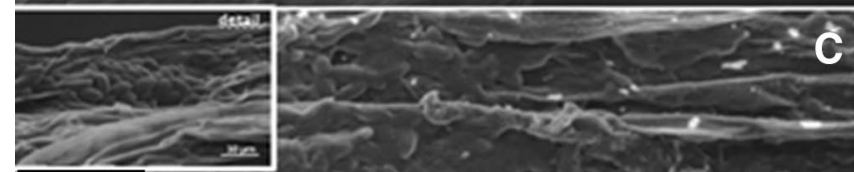

\section{L1 24h}

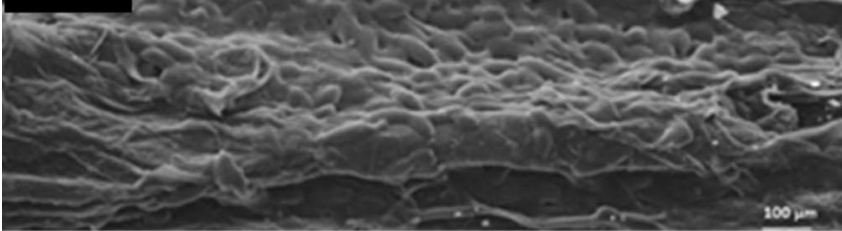

Fig. 5 Scanning electron micrographs (SEM) of bean roots (surface) treated with water (control) (a) and Aureobasidium pullulans (L1 strain) cells suspension $\left(10^{7}\right.$ cells $\left./ \mathrm{mL}\right)$. Root tissues were collected at different times from the treatment $(3,24,48 \mathrm{~h})$ (b-d, respectively).

genera of soil yeasts are Candida spp., Cryptococcus spp., Rhodotorula spp., and Aureobasidium spp. (Spencer and Spencer 1997).

Our results also showed the potential of A. pullulans L1 and L8 strains to be involved in promoting leguminous plant growth.

The two strains showed a different efficacy against the target pathogen, but both displayed the same main mechanisms of actions against $R$. solani, as suggested by the fact that both strains produced non-volatile metabolites and formed biofilm around leguminous roots.

The detected non-volatile organic compounds, mainly complex carbohydrates (such as pullulan or other $\beta$-glucans), degrading enzymes, cyclic depsipeptides and siderophores, inhibited the pathogen mycelial growth by $87.9 \%$. More in detail, spectroscopic data (FT-IR and Raman techniques) revealed that L1 strain has higher production of lytic enzymes and complex carbohydrates. Pullulan and other polysaccharides may improve the biofilm formation and therefore adhesion, thus explaining the better performance of L1 on polystyrene plates. Moreover, FT-IR spectra showed that the polysaccharide production by L8 strain is characterized by a reduced chain length and average molecular weight of the polymer (Shingel et al. 2002), thus leading to a less efficient biofilm formation. Interestingly, the highest inhibition showed by L1 in in vivo test, can be related to a higher production of degrading enzymes (i.e., amylases, proteases

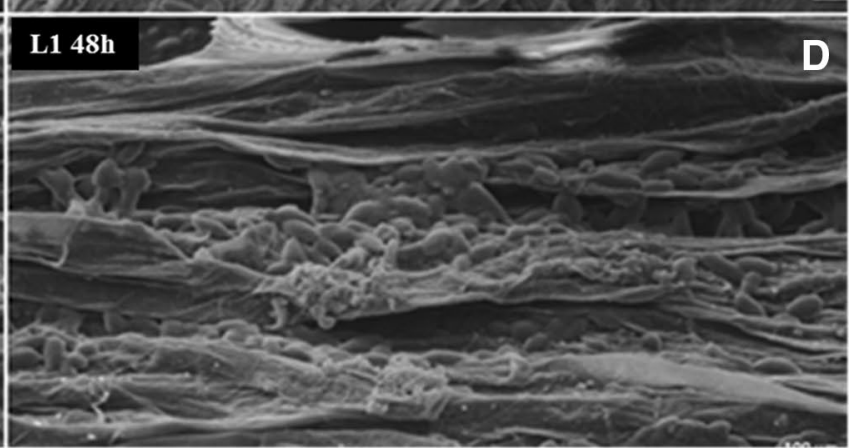

SEM shown, $100 \times$ magnification in all images and $10 \times$ in the details images. Only images of L1 on bean roots were reported as no significant optical differences were founded between the two strains and the plant species

or lipases) and to a different production of aureobasidins, a class of antifungal compounds typical of $A$. pullulans (Bozoudi and Tsaltas 2018) and siderophores. Aureobasidins are derivatives of cyclic depsipeptides, which were reported to be synthesized also by Streptomyces (Um et al. 2013; Bae et al. 2015) and by marine sponges (Dahiya et al. 2016) and possessing antifungal properties. Different strains of $A$. pullulans were reported to produce a different mix of these compounds which contain peculiar amino acids such as proline, leucine and phenylalanine (Takesako et al. 1991). Wang et al. 2009, first characterized a hydroxamate siderophore produced by a strain of $A$. pullulans, demonstrating a strong inhibition towards the pathogenic Vibrio anguillarum. Both FT-IR and Raman spectra confirmed the presence of hydroxamate derivatives by several diagnostic bands (Cozar et al. 2006) $\left(1564,1330,630\right.$ and $530 \mathrm{~cm}^{-1}$ in the IR spectra and 1292, 880, 640, 620 and $480 \mathrm{~cm}^{-1}$ in the Raman spectra). The production of the siderophores in L1 and L8 strains and their chemical nature is under investigation and will be assessed in a future study. Following our results, the synthesis of antibiotics compounds can be considered as an important system for the inhibition of soil-borne pathogen growth (Rothrock and Gottlieb 1981; Punja and Utkhede 2003).

VOCs displayed a reduced inhibitory effect on $R$. solani mycelium growth (10.5\%) but at the same time significantly influenced the production of CWDEs of the soil pathogen. 
VOCs seemed to inhibit mainly the activity of pectinase and cellulase pathogenic enzymes secreted by $R$. solani. It can be assumed that VOCs could reduce the decomposition of plant tissues by activating antioxidant enzymes to reduce plant cell damage and activate disease resistance enzymes to enhance the resistance of bean or soybean plants to $R$. solani and inhibit its growth.

Conversely, previous studies presented a great inhibitory effect exerted by L1 and L8 VOCs against the main fruit postharvest pathogens (Di Francesco et al. 2015, 2020a). This aspect supports the hypothesis that each antagonist employs different mechanisms to suppress different pathogens (Whipps 2001; Botha 2011) and its efficacy varies among the different pathosystems.

Biofilm formation is considered an important and strong mechanism of postharvest antagonistic microorganisms during the colonization of the substrate and fruit wounds (Klein and Kupper 2018) to prevent fungal attack. In this study, L1 and L8 showed the ability to rapidly colonize plant roots, one of the principal requirements for a BCA of soil-borne fungal pathogens, probably enhanced by the root's exudates (Van Overbeek and Van Elsas 1995). Rhizosphere ability should be considered a prerequisite for successful biological control of root diseases, and lack of reliable biological control observed in many studies may be related to the failure to adequately colonize roots (Weller 1988).

Our results indicated how both strains began to produce cells biofilm starting from $3 \mathrm{~h}$ by roots contact. After only $48 \mathrm{~h}$, the surface of the root was totally covered by cells biofilm. The strains might preemptively colonize the rhizosphere and root without directly competing for the same site with the pathogen.

El-Tarabily (2004) reported that C. valida and T. asahii colonized $95 \%$ of roots by 6 days after radical emergence, whereas R. glutinis colonized $90 \%$ of roots after 8 days, showing how roots could be colonized at different times by different yeast species.

Considerable attention must be given to the detected ability of L1 and L8 strains to promote bean and soybean plant growth, in particular of roots and leaves. Plant growthpromoter microorganisms (PGPs) can act directly or indirectly. Indirect effects are mainly related to the production of siderophores (Buysens et al. 1996) which increase plant growth by decreasing the activities of pathogens. Our strains previously displayed the ability to produce a considerable amount of siderophores (1.2 and $1.4 \mathrm{mg} / \mathrm{mL}$ by $\mathrm{L} 1$ and $\mathrm{L} 8$ respectively) (article under review) competing for peach nutrients with Monilinia laxa, brown rot agent of stone fruit. As previously mentioned, spectroscopic investigations have highlighted the presence of siderophores in both L1 and L8 strains. However, PGPs can directly affect plant physiological conditions promoting the nitrogen fixation (Cocking 2003) or the production of auxins, gibberellins, and cytokinins (Bottini et al. 2004; Kuklinsky-Sobral et al. 2004).

Recently, there is great interest in the agricultural sector to use PGPs (e.g., microorganisms, plant extracts, polyamines) (Compant et al. 2005) independently from pathogen presence, and additionally for reducing the chemical inputs (Gerhardson 2002).

For these reasons, an investigation of the capability of both strains to induce resistance in the treated plants can be foreseen. Verification of the siderophore production and the non-volatile compounds involvement in the inhibition of the target soil pathogen could be planned. Similarly, as previously reported for apple wood (Rusin et al. 2019), the role of both strains as endophytic microorganisms in plant roots warrant examination.

Acknowledgements Open access funding provided by Alma Mater Studiorum - Università di Bologna within the CRUI-CARE Agreement.

\section{Compliance with ethical standards}

Conflict of interest The authors declare that they have no known competing financial interests or personal relationships that could have appeared to influence the work reported in this paper.

Open Access This article is licensed under a Creative Commons Attribution 4.0 International License, which permits use, sharing, adaptation, distribution and reproduction in any medium or format, as long as you give appropriate credit to the original author(s) and the source, provide a link to the Creative Commons licence, and indicate if changes were made. The images or other third party material in this article are included in the article's Creative Commons licence, unless indicated otherwise in a credit line to the material. If material is not included in the article's Creative Commons licence and your intended use is not permitted by statutory regulation or exceeds the permitted use, you will need to obtain permission directly from the copyright holder. To view a copy of this licence, visit http://creativecommons.org/licenses/by/4.0/.

\section{References}

Aghatabay NM, Parali O, Zaim O, Baydar C, Dulger B (2014) Synthesis, structural aspects, antimicrobial activity and ion transportation investigation of four new $[2+2]$ condensed 24-membered cycloheterphane peptides. J Incl Phenom Macro Chem 79:415-424

Ahed AHM, Kamil SJ (2013) Biological control of sbean root rot disease caused by Rhizoctonia solani under green house and field conditions. Agric Biol J N Am 4:512-519

Akladious SA, Gomaa EZ, El-Mahdy OM (2019) Efficiency of bacterial biosurfactant for biocontrol of Rhizoctonia solani (AG-4) causing root rot in faba bean (Vicia faba) plants. Eur J Plant Pathol 153:1237-1257

Bae M, Chung B, Oh KB, Shin J, Oh DC (2015) Hormaomycins B and $C$ : new antibiotic cyclic depsipeptides rom a marine mudflatderived Streptomyces sp. Mar Drugs 13:5187-5200

Botha A (2011) The importance and ecology of yeasts in soil. Soil Biol Biochem 43:1-8 
Bottini R, Cassan F, Piccoli P (2004) Gibberellin production by bacteria and its involvement in plant growth promotion and yield increase. Appl Microbiol Biotechnol 65:497-503

Bozoudi D, Tsaltas D (2018) The multiple and versatile roles of Aureobasidium pullulans in the vitivinicultural sector. Fermentation 4:85-99

Brewer MT, Lang L, Fujimura K, Dujmovic N, Gray S, van der Knaap E (2006) Development of a controlled vocabulary and software application to analyze fruit shape variation in tomato and other plant species. Plant Physiol 141:15-25

Buysens S, Heungens K, Poppe J, Hofte M (1996) Involvement of phyochelin and pyoverdine in suppression of Phytium-induced damping-off of tomato by Pseudomonas aeruginosa 7NSK2. Appl Environ Microbiol 62:865-871

Cardoso JE, Echandi E (1987) Biological control of Rhizoctonia root rot of snapbean with binucleate Rhizoctonia-like fungi. Plant Dis $71: 167-170$

Cocking EC (2003) Endophytic colonization of plant roots by nitrogenfixing bacteria. Plant Soil 252:169-175

Compant S, Duffy B, Nowak J, Clement C, Barka EA (2005) Use of plant growth-promoting bacteria for biocontrol of plant diseases: principles, mechanisms of action, and future prospects. Appl Environ Microbiol 71:4951-4959

Cozar O, Leopold N, Jelic C, Chis V, David L, Mocanu A, TomoaiaCotisel M (2006) IR, Raman and surface-enhanced Raman study of desferrioxamine B and its Fe(III) complex, ferrioxamine B. J Mol Struct 788:1-6

Dahiya R, Singh S, Sharma A, Chennupati SV, Maharaj S (2016) First total synthesis and biological screening of a Proline-rich cyclopeptide from a Caribbean marine sponge. Mar Drugs 14:228

Di Francesco A, Ugolini L, Lazzeri L, Mari M (2015) Production of volatile organic compounds by Aureobasidium pullulans as a potential mechanism of action against postharvest fruit pathogens. Biol Control 81:8-14

Di Francesco A, Ugolini L, D’Aquino S, Pagnotta E, Mari M (2017) Biocontrol of Monilinia laxa by Aureobasidium pullulans strains: insights on competition for nutrients and space. Int J Food Microbiol 248:32-38

Di Francesco A, Calassanzio M, Ratti M, Mari M, Folchi A, Baraldi E (2018a) Molecular characterization of the two postharvest biological control agents Aureobasidium pullulans L1 and L8. Biol Control 123:53-59

Di Francesco A, Mari M, Ugolini L, Baraldi E (2018b) Effect of Aureobasidium pullulans strains against Botrytis cinerea on kiwifruit during storage and on fruit nutritional composition. Food Microbiol 72:67-72

Di Francesco A, Mari M, Roberti R (2018c) Defence response against postharvest pathogens in hot water treated apples. Sci Hortic 227:181-186

Di Francesco A, Di Foggia M, Baraldi E (2020a) Aureobasidium pullulans volatile organic compounds as alternative postharvest method to control brown rot of stone fruits. Food Microbiol 87:103395

Di Francesco A, Rusin C, Di Foggia M, Marceddu S, Rombolà A, Botelho RV, Baraldi E (2020b) Characterization of apple cultivar susceptibility to Neofusicoccum parvum Brazilian strains. Eur J Plant Pathol 156:939-951

El-Tarabily KA (2004) Suppression of Rhizoctonia solani diseases of sugar beet by antagonistic and plant-growth promoting yeasts. J Appl Microbiol 96:69-75

El-Tarabily KA, Sivasithamparam K (2006) Potential of yeasts as biocontrol agents of soil-borne fungal plant pathogens and as plant growth promoters. Mycoscience 47:25-35

Filonow AB (1998) Role of competition for sugars by yeasts in the biocontrol of gray mold of apple. Biocontrol Sci Technol 8:243-256

Gerhardson B (2002) Biological substitutes for pesticides. Trends Biotechnol 20:338-343
Klein MN, Kupper KC (2018) Biofilm production by Aureobasidium pullulans improves biocontrol against sour rot in citrus. Food Microbiol 69:1-10

Kohl J, Kolnaar R, Ravensberg WJ (2019) Mode of action of microbial Biological Control Agents against plant diseases: relevance beyond efficacy. Front Plant Sci 10:845

Kotze C, Niekerk J, van Halleen F, Mostert L, Fourie P (2011) Evaluation of biocontrol agents for grapevine pruning wound protection against trunk pathogen infection. Phytopathol Mediterr 50:247-263

Kuklinsky-Sobral J, Araujo WL, Mendes R, Geraldi IO, PizziraniKleiner AA, Azevedo JL (2004) Isolation and characterization of soybean-associated bacteria and their potential for plant growth promotion. Environ Microbiol 6:1244-1251

McLaughlin RJ, Wilson CL, Chalutz E, Kurtzman CP, Fett WF, Osman SF (1990) Characterization and reclassification of yeasts used for biological control of postharvest diseases of fruits and vegetables. Appl Environ Microbiol 56:3583-3586

Müller Schmidt T, Thomé AHE, Sperotto RA, Eichelberger Granada C (2018) Effect of rhizobia inoculation on the development of soilborne pathogens infecting common bean plants. Eur J Plant Pathol 153:687-694

Parafati L, Vitale A, Restuccia C, Cirvilleri G (2015) Biocontrol ability and action mechanism of food-isolated yeast strains against Botrytis cinerea causing post-harvest bunch rot of table grape. Food Microbiol 47:85-92

Phaff HJ, Starmer WT, Miranda M, Miller MW (1978) Pichia heedii, a new species of yeast indigenous to necrotic cacti in the North American Sonoran Desert. Int J Syst Bacter 28:326-331

Punja Z, Utkhede RS (2003) Using fungi and yeasts to manage vegetable crop diseases. Trends Biotechnol 21:400-407

Rothrock CS, Gottlieb D (1981) Importance of antibiotic production in antagonism of selected Streptomyces species to two soil-borne plant pathogens. J Antibiot 34:830-835

Rusin C, Di Francesco A, Di Foggia M, D’Aquino S, Rombolà A, Tugnoli V, Vasconcelos Botelho R, Baraldi E (2019) An emerging problem affecting apple production: Neofusicoccum parvum. Aureobasidium pullulans L1 and L8 strains as an alternative control strategy. Biol Control 134:157-162

Shingel KI (2002) Determination of structural peculiarities of dexran, pullulan and g-irradiated pullulan by Fourier-transform IR spectroscopy. Carbohydr Res 337:1445-1451

Spencer JFT, Spencer DM (1997) Ecology: where yeasts live. Yeasts in natural and artificial habitats. Springer, Berlin, Heidelberg

Takesako K, Ikai K, Haruna F, Endo M, Shinamaka K, Sono E, Nakamura T, Kato I, Yamaguchi H (1991) Aureobasidins, new antifungal antibiotics. Taxonomy, fermentation, isolation, and properties. J Antibiot 44:919-924

Thiessen LD, Woodward JE, (2012) Diseases of peanut caused by soilborne pathogensin the Southwestern United States: Review article. International Scholarly Research Network ISRN Agronomy

Tu AT (1982) Raman spectroscopy in biology: principles and applications. Ed. John Wiley \& Sons, 1982 New York USA (Chapter 3: Peptides and Proteins; Chapter 4: Enzymes and Immunoglobulins; Chapter 8: Carbohydrates).

Um S, Choi TJ, Kim H, Kim BY, Kim SH, Lee SK, Oh KB, Shin J, Oh DC (2013) Ohmyungsamycins A and B: cytotoxic and antimicrobial cyclic peptides produced by Streptomyces sp. from a volcanic Island. J Org Chem 78:12321-12329

Van Overbeek LS, Van Elsas JD (1995) Root exudate-induced promoter activity in Pseudomonas fluorescens mutants in the wheat rhizosphere. Appl Environ Microbiol 61:890-898

Wang WL, Chi ZM, Chi Z, Li J, Wang XH (2009) Siderophore production by the marine-derived Aureobasidium pullulans and its antimicrobial activity. Biores Technol 100:2639-2641

Weller DM (1988) Biological control of soil-borne plant pathogens in the rhizosphere with bacteria. Ann Rev Phytopathol 26:379-407 
Whipps JM (2001) Microbial interactions and biocontrol in the rhizosphere. J Exp Bot 52:487-511

Wilson CL, Wisniewski ME (1989) Biological control of postharvest diseases of fruits and vegetables: an emerging technology. Ann Rev Phytopathol 27:425-441

Zhang D, Spadaro D, Garibaldi A, Gullino ML (2010) Potential biocontrol activity of a strain of Pichia guilliermondii against grey mold of apples and its possible modes of action. Biol Control 57:193-201

Zhbankov RG, Firsov SP, Korolik EV, Petrov PT, Lapkovski MP, Tsarenkov VM, Marchewka MK, Ratajczak H (2000) Vibrational spectra and the structure of medical biopolymers. J Mol Struct 555:85-96
Publisher's Note Springer Nature remains neutral with regard to jurisdictional claims in published maps and institutional affiliations. 